\title{
Sebastián Martín-Retortillo: jurista, académico, político
}

\author{
Javier Arenas Bocanegra \\ Vicepresidente $2 .^{\circ}$ del Gobierno
}

Parece cierta aquella consideración del viejo Benavente sobre las semblanzas: que honran tanto a quienes son objeto de su distinción como a quienes las escriben. Considero un honor colaborar en estas páginas dedicadas a Sebastián Martín-Retortillo, que, además de un experto Profesor y Académico, que tanto aportó al desarrollo del Derecho Administrativo en España, con más de ochenta obras publicadas, en solitario o en colaboración, fue un buen Ministro de Administraciones Públicas. Lo fue, además, en una etapa —entre 1980 y 1981 - especialmente interesante en la construcción de nuestro Estado de las Autonomías. El mapa autonómico se cerraría, en sus líneas generales y salvo la excepción de las ciudades de Ceuta y Melilla, en 1983, cuando se aprobaron los últimos Estatutos de Autonomía que ya han cumplido dos décadas.

Recuerdo aún cuando conocí a Martín-Retortillo, y recuerdo que pensé que estaba ante un hombre del que se podía aprender siempre algo; que tenía mucho que decir y que contar. Quizá su condición de Profesor forjó su carácter en la cercanía, pues fue Catedrático en varias Universidades, desde la de Santiago de Compostela a la de Valladolid, y desde la de Barcelona a la Autónoma y a la Complutense de Madrid. Pienso que el Profesor estaría de acuerdo en esa afirmación de Ortega, sobre la misión de la Universidad, que a su juicio debía evolucionar desde el concepto de una Institución centrada en la adquisición de un título útil al ejercicio de una profesión, hacia el objetivo de formar globalmente a la persona.

Resulta oportuno que el Instituto Nacional de Administración Pública dedique, precisamente en su Revista de Estudios de la Administración Local, un número monográfico a la figura del profesor Martín-Retortillo. Él participó como experto en 1978 en la Comisión oficial redactora del Proyecto de Ley de Régimen Local, como lo había hecho ya en otros proyectos legislativos significativos, entre ellos la Ley del Patrimonio Artístico en 1976 o la Ley de Aguas en 1972, y también aportó mucho al Instituto de Estudios de Administración Local.

Como diputado por Huesca en la primera legislatura, fue Ponente de los Estatutos de Autonomía vasco y catalán, formando parte además de la 
Ponencia del Congreso que trabajó sobre el Proyecto de Ley del Tribunal Constitucional, Institución que está cumpliendo un papel importantísimo de vertebración y garantía de los principios consensuados de nuestro texto constitucional. Es decir, que tanto en su vertiente académica y en su profesión de jurista, como en su dedicación política, Martín-Retortillo ha contribuido a construir la realidad actual de nuestra estructura territorial, moderna y descentralizada. Si tenemos hoy un Estado plenamente integrado en la Unión Europea y que se cuenta entre los más descentralizados del Continente, es por la contribución plural de toda una serie de personas con capacidad de encuentro y diálogo que trabajaron en los primeros años de nuestra democracia; y que tuvieron además la intuición suficiente para emprender las reformas que los españoles demandaban a sus representantes políticos.

Hacer la semblanza de Martín-Retortillo nos lleva a pensar en la realidad nacida de aquel proyecto compartido que se plasmó en la Constitución de 1978. Y no me parece fuera de lugar afrontar aquí una breve reflexión sobre la necesidad de recuperar, al día de hoy, el espíritu de esa etapa vivida activamente por Sebastián, que para algunos ya es histórica y que, sin duda, constituye un ejemplo de moderación y solidaridad que no tiene fácil paralelismo ni en otras etapas de nuestra propia historia, ni en otros países.

Hoy hablamos de la transición como de una realidad del pasado, histórica, porque hablamos desde una democracia plenamente consolidada. No somos ya una joven democracia que ha de encontrar su identidad. Pero el hecho de que este año celebremos un cuarto de siglo de la Constitución española, que tengamos una vida política moderna en la que todos podemos participar, y un modelo de Estado consolidado, no significa que no debamos seguir trabajando de forma permanente para hacer una política más viva, más cercana a los ciudadanos, y más eficaz en términos de calidad y de servicio público.

Los problemas que actualmente afrontamos son distintos que en el momento en que Sebastián Martín-Retortillo fue Subsecretario del Ministerio de Educación y Ciencia, entre 1976 y 1977, con Aurelio Menéndez de Ministro; y también diferentes a las cuestiones que se planteaban en los años en que ejerció el cargo de Ministro de Administraciones Públicas, siendo Presidente del Gobierno Adolfo Suárez. Hoy tenemos un Estado como he dicho descentralizado - ese Estado por el que Sebastián siempre sintió la pasión del docente-, un Estado en el que las Comunidades Autónomas han incrementado sus competencias, sus presupuestos y su personal, y en el que la sociedad ha recuperado protagonismo. 
Martín-Retortillo habría cumplido en febrero 72 años. Hace muy poco que nos dejó: el 19 de octubre del pasado año 2002 y hacía muy poco también que había sido elegido académico de número en la Real Academia de Ciencias Morales y Políticas, ocupando la vacante de Laureano López Rodó. Tuvo, por tanto, la oportunidad de comprobar cómo había evolucionado España desde aquellos momentos en que gestionó buena parte de sus transformaciones, jurídicas y políticas, trasladando a la vida pública los cambios sociales. Había estudiado el carácter de este proceso, que ha tenido mucho que ver con el escalonamiento de las tareas de la reforma, permitiendo resolver las situaciones potencialmente conflictivas sin rupturas ni traumas. Y él mejor que nadie conocía todas las debilidades y las grandezas de las instituciones democráticas; y, conociéndolas, sabía y valoraba cuánto nos ha costado a los españoles llegar donde hemos llegado.

Sus últimos libros, publicados en el año 2000: Las obras hidráulicas en la Ley de Aguas y Fragmentos del Derecho Administrativo; así como la edición en la que colaboró en el mismo año 2002, Breves acotaciones sobre el desarrollo tecnológico y el sistema jurídico administrativo, ponen bien de manifiesto toda una vida entregada al trabajo; y destacan asimismo la modernidad de los planteamientos de Martín-Retortillo. Evidentemente, el desarrollo tecnológico, la e-administración, es uno de los aspectos cruciales para la competitividad de nuestras Administraciones. Por ello hoy estamos construyendo en España una Administración Electrónica y creando puentes entre las distintas Administraciones Públicas, desde la Europea a la Administración General del Estado, las Comunidades Autónomas y las Corporaciones Locales. Contamos con herramientas más eficientes como las nuevas tecnologías, pero también hemos de responder a demandas mucho más exigentes de los ciudadanos, tal y como debe ser en una sociedad avanzada y en progreso.

Esta monografía dedicada a Martín-Retortillo por el INAP es un acierto. Desde luego lo es reivindicar su figura y su condición de hombre extraordinariamente ilustrado y entregado a la defensa de las instituciones democráticas del Estado. Si hay que definir en pocas palabras a Sebastián Martín-Retortillo, yo diría que fue: político por convicción, jurista por oficio y docente por exigencia personal. 